\title{
Article \\ Smartphones and Learning: An Extension of M-Learning or a Distinct Area of Inquiry
}

\author{
Kendall Hartley ${ }^{1, *(1)}$ and Alberto Andújar ${ }^{2}$ (D) \\ 1 Department of Teaching \& Learning, University of Nevada, Las Vegas, Las Vegas, NV 89154, USA \\ 2 Faculty of Humanities, University of Almería, 04120 La Cañada, Spain; alberto.andujar@ual.es \\ * Correspondence: kendall.hartley@unlv.edu
}

Citation: Hartley, K.; Andújar, A. Smartphones and Learning: An Extension of M-Learning or a Distinct Area of Inquiry. Educ. Sci. 2022, 12, 50. https://doi.org/10.3390/ educsci12010050

Academic Editor: Albert Ziegler

Received: 9 December 2021

Accepted: 10 January 2022

Published: 14 January 2022

Publisher's Note: MDPI stays neutral with regard to jurisdictional claims in published maps and institutional affiliations.

Copyright: (C) 2022 by the authors. Licensee MDPI, Basel, Switzerland. This article is an open access article distributed under the terms and conditions of the Creative Commons Attribution (CC BY) license (https:// creativecommons.org/licenses/by/ $4.0 /)$.

\begin{abstract}
The smartphone has become an integral part of the education landscape. While there has been significant smartphone research in education under the guise of m-learning, the unique role of the device suggests that m-learning may not be an appropriate characterization. The purpose of this paper is to review the use of m-learning as a primary descriptor for smartphone- and learning-related research. In support of this goal, the paper reviews the definitions associated with m-learning, smartphones, and related technologies from the perspective of educational research. In addition, a review of author keywords of research on smartphones in education is used to provide context to the classification of the research. Finally, three theoretically guided smartphone programs are presented as evidence of the unique nature of smartphone and learning research. This review concludes with recommendations for the characterization of future research.
\end{abstract}

Keywords: smartphone; m-learning; self-regulated learning; technology acceptance model; selfdetermination theory

\section{Introduction}

The term smartphone in the title of this review is intentional. While mobile learning and m-learning may be more commonly associated with research in this area, much of that research is decidedly different from research where the smartphone is the primary information and communications technology (ICT) device. This paper aims to clarify the unique role of the smartphone in teaching, learning, and educational research and contrast that role with that of m-learning. The smartphone introduces a combination of attributes that have substantial implications for learning research. These attributes are not currently captured in the commonly used classifications used in ICT research.

The smartphone is arguably one of the most impactful technological innovations to be introduced into society in general and education in particular. There have been two other comparable technological innovations in education in the past fifty years. The introduction of the personal computer in the '80s and the Internet in the '90s impacted many (not all) teaching and learning environments.

\section{Purpose}

The smartphone- and learning-related research that has been produced in the past decade is substantial and of great interest to practitioners and researchers. However, comingling this research with that of other mobile technologies (e.g., classroom tablets) and initiatives (e.g., one-to-one computing) is problematic. The purpose of this paper is to review and critique the use of m-learning as a primary descriptor for smartphone and learning related research. Due to its ubiquity, flexibility, and utility, the smartphone presents distinct opportunities and challenges that justify its own place in the educational technology research lexicon. In particular, while classifying research on smartphones and learning as mobile learning (or m-learning) is common, it is less than ideal. After a brief 
historical overview of the rapid adoption of the smartphone, the paper will begin with a review of relevant definitions found in the education research literature. Subsequently, descriptors of research related to smartphones and learning will be compared to the related phrases such as mobile learning, m-learning, ubiquitous learning, and personal technology. Next, a purposeful selection of theoretically grounded research studies is presented as indicators of the unique contributions of smartphone-focused educational research. The paper concludes with a summary and suggestions for the classification of subsequent smartphone and learning research.

\section{Technology Adoption and Definitions}

\subsection{Rates of Technology Adoption}

The personal computer and the Internet exhibited relatively limited adoption percentages compared to the smartphone. The Pew Institute reported that $35 \%$ of respondents reported owning a smartphone in 2011 [1]. In ten years, that percentage jumped to $85 \%$ overall and $96 \%$ amongst $18-29$ year-olds. A rough comparison can be made with the personal computer that received a big boost with the introduction of the Macintosh during the 1984 Super Bowl (see Figure 1). In that year, 8.2\% of households reported having a home computer. Thirteen years later, in 1997, the number rose to $36.6 \%$.

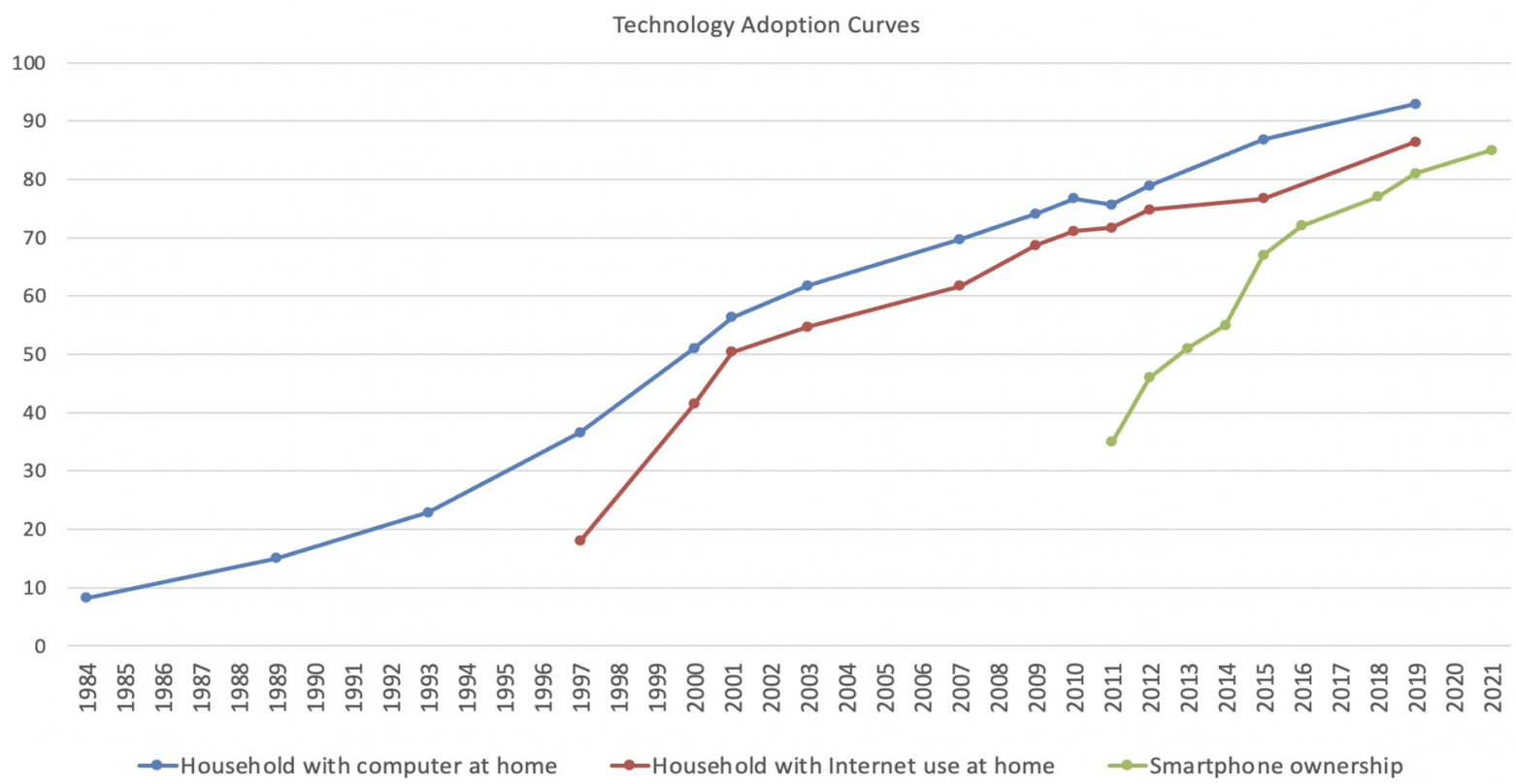

Figure 1. Adoption and penetration of representative technologies in the United States. Sources: Household computer and Internet use. U.S. Census Bureau, Current Population Survey (19842012) [2]; American Community Survey, 2015 and 2019 [3]; Smartphone ownership [1].

United States home internet subscriptions follow a similar trend. In 1997, less than $20 \%$ of households had an internet connection. Ten years later, the percentage of connected homes rose to $60 \%$ and plateaued in 2015 at $74 \%$. While all three adoptions are significant and rapid, the smartphone stands out as the one innovation that has achieved nearly universal personal adoption.

The educational implications of the personal computer and the Internet were substantial. The Apple Computer company made substantial investments to encourage the adoption of the personal computer in the classroom. The Apple Classrooms of Tomorrow (ACOT) initiative was presented as a research and development collaboration between the company and public education institutions and resulted in millions of students having regular access to computers to support their learning [4]. The Internet also has had an unquestionable impact on schooling and learning research [5]. The Internet has provided 
educational applications and a medium for students to enroll, attend, and otherwise engage in school.

The smartphone has effectively combined the two innovations and placed it in the backpack of virtually every secondary and post-secondary student. In reality, the smartphone spends more time in the student's hands than in the backpack. A study of smartphone use by students enrolled in a U.S. Midwest university found that they averaged 122 pickups and over $5 \mathrm{~h}$ of use each day [6]. This usage appears to occur throughout the entire day. A 2019 study found that $95 \%$ of college students reported using their smartphones in the hour preceding going to sleep [7]. Many lecturers permit the use of smartphones in the college classroom and perceive them as an important adjunct to instruction [8,9]. The COVID-19 pandemic and the rapid move to emergency remote teaching (ERT) intensified the increasing reliance on mobile learning in general [10] and smartphones in particular [11]. This included innovative approaches to the delivery of instruction that included cloud-based computing approaches that enabled greater engagement from students via the smartphone [12].

\subsection{Definitions}

\subsubsection{Smartphone}

While smartphones such as the Blackberry were widely available in the early part of this century, the acknowledged critical event that stimulated mass adoption was the iPhone's introduction in 2007. This device soon transcended boundaries that heretofore had been substantial. Work, school, family, and leisure would soon become intermixed on one device. The only separation that might be found now is how an individual arranges the apps on the smartphone home screen to distinguish between work, school, and personal.

The smartphone is a deeply personal device. It is not shared. While the device's functionality is far-reaching, one missing feature is the capability to change users without a reset of the operating system. The smartphone is so personal that it has become a primary tool for verifying one's identity (e.g., two-factor authentication).

The smartphone is an incredibly powerful, multifunctional computer that includes advanced micro-sensors that were unimaginable anywhere other than in science fiction media a generation ago. Consider the motion sensors now found in all modern smartphones. These include highly sensitive accelerometers and gyroscopes that are powerful enough to examine the range of motion of an ankle or spine [13]. One can find similar, ever-expanding capabilities with video, audio, GPS, and high-speed data transmission.

\subsubsection{Mobile Learning (M-Learning)}

M-learning precedes the smartphone revolution, as indicated by a groundswell of research publications and conferences in the early 2000s [14]. Attempts to define M-learning are not without challenges:

"Attempts to develop the conceptualisations and evaluation of mobile learning, however, must recognise that mobile learning is essentially personal, contextual, and situated; this means it is 'noisy' and this is problematic both for definition and for evaluation." ([14] p. 1)

While this definition includes the term personal, that is questionable as it relates to educational research. In a systematic literature review, Fu and Hwang found that the typical mobile learning intervention includes a classroom set or a temporarily assigned device such as a tablet or laptop [15]. This review also revealed that more recent research has begun incorporating students' personal smartphones into interventions.

One of the earliest uses of the term m-learning was by Clark Quinn in the periodical LineZine [16]:

It's elearning through mobile computational devices: Palms, Windows CE machines, even your digital cell phone. Let's call them information appliances (IAs), and ask what's cool about this? (p. 1) 
For many, m-learning is intricately linked to e-learning and distance education [17]. For example, m-learning has been described as simply the next generation of e-learning [18,19]. A recent review of mobile learning research studies highlighted the changing nature of mobile learning. The focus of early studies was on classroom learning; however, subsequent work explores a wider variety of settings [20].

\subsubsection{Related Technologies}

In order of introduction into the mainstream, three related technologies are worth a brief review. The precursor to the tablet is the Personal Digital Assistant (PDA). While the lifespan of the PDA was relatively brief, it did foreshadow the smartphone and tablet in many ways. Apple's Newton computer, introduced in 1993 and discontinued in 1998, is most closely associated with the PDA phase [21]. The appearance of PDAs in the classrooms and learning research was limited.

One can best describe the tablet computer as merging the laptop computer and the smartphone. While Apple's iPad popularized the tablet computer, various iterations of similar devices have been around as long as the laptop. The feature of the tablet computer that most often distinguishes it from the laptop is the absence of a physical keyboard and a touch screen as the primary user interface. Tablets have been regularly introduced into classrooms and are the subject of substantial learning research [15].

Wearable technologies are computing devices or accessories that are affixed to the person. The most common current example is the smartwatch (e.g., Fitbit and Apple Watch). U.S. sales of smartwatches doubled between 2016 (9 million) and 2018 (18.8 million) [22]. As of 2019, 25\% of U.S. adults under 50 reported owning a smartwatch [23]. In many ways, these devices are extensions of the smartphone as much of the capacity depends upon a paired phone.

\section{M-Learning and Smartphones as Educational Research Descriptors}

Of particular interest for this work is the common use of two research descriptors for smartphone and learning research. These descriptors are chosen by the author to assist in classifying the work. Mobile learning and m-learning are used interchangeably and will be treated as one in the subsequent discussion. The second common descriptor used for this research is smartphone. The choice of one descriptor over the other is often unclear. For example, in two studies whose titles reference smartphone use in the classroom, one used the smartphone descriptor [24] while the other chose mobile learning [25]. As indicated in the preceding definitions, there are important differences between these two lines of research. An exploration of the current use of these two research descriptors will address in more detail the current state of smartphone and learning research.

The Web of Science Core Collection (formerly the Social Science Citation Index) was consulted to determine the frequency with which the keywords mobile learning (including m-learning) and smartphone(s) were used by authors in the recent educational research publications concerned with smartphones and learning. This analysis intends not to present a comprehensive review of the use of these keywords but rather to provide insight into the current practices of ICT researchers.

Searching the collection for articles with the subject 'Educational Research' published in 2015-2020 with various author keywords and abstract terms provides some interesting information regarding the overall frequency and co-occurrence of m-learning and smartphones. For example, the keywords mobile learning and m-learning are more frequent than smartphone(s) (736 vs. 183). Searching the abstracts of articles that use the mobile learning keywords reveals that $14.7 \%$ of them include the term smartphone or phone (see Figure 2 for a visual representation and Table 1 for a complete record of the searches). Similarly, in papers that use the keyword smartphone, $10.4 \%$ use the terms m-learning or mobile learning in the abstract. 

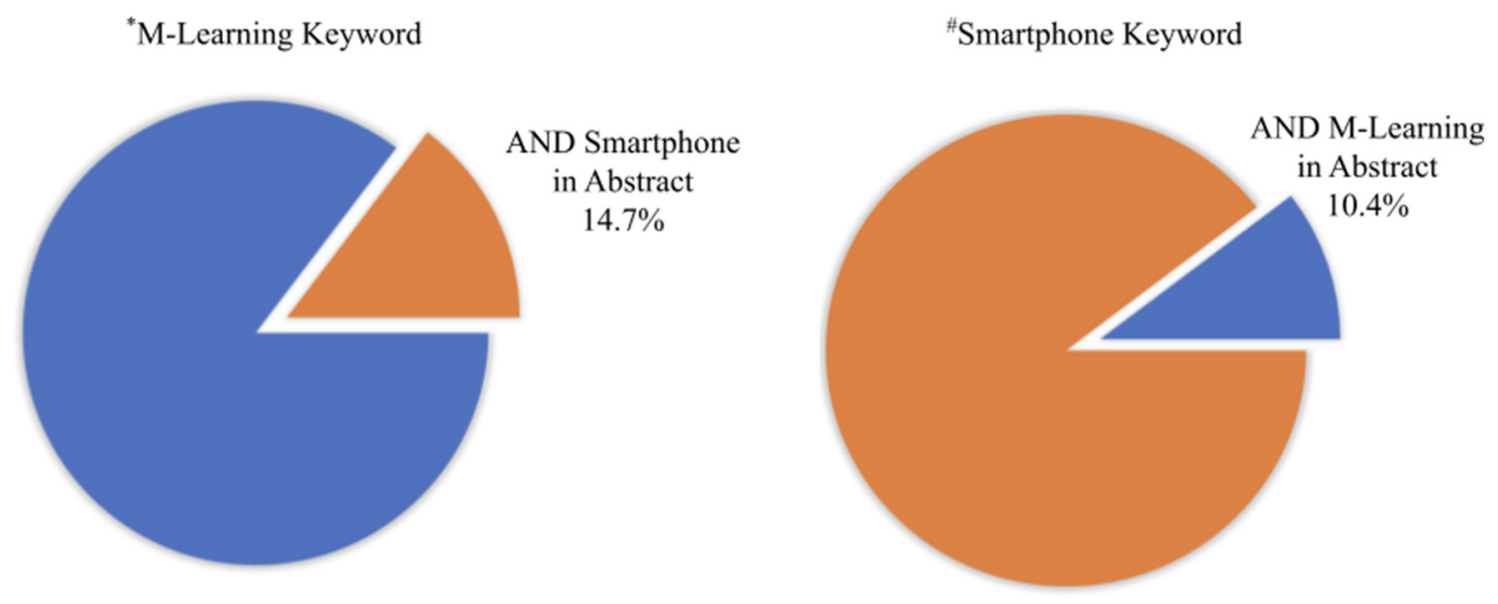

Figure 2. M-Learning and Smartphone in Keywords and Abstract. * M-Learning or "Mobile Learning" as an author chosen keyword. " Smartphone or smartphones as an author chosen keyword.

A search for articles that use the keywords mobile learning AND smartphone produces only 31 results (see Table 1 search \#5). In other words, of the $919(736+183)$ educational research articles where authors choose either mobile learning or smartphone keywords, only 31 or $3.7 \%$ use both. These results indicate that authors either assume that one keyword is inclusive of the other (and thus no need to include it) or view them as independent. 
Table 1. Author keywords Web of Science core collection.

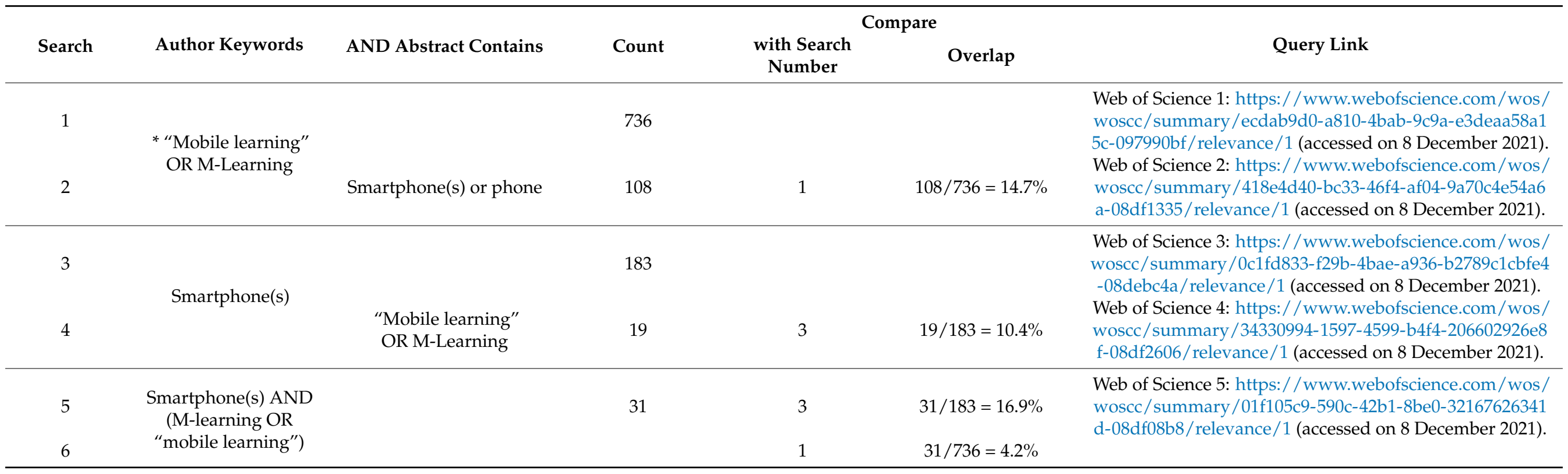

Notes: Category [Educational Research], Years [2015-2020], Publication type: [Article], * Mobile-learning and m-learning did not produce additional results. 


\section{Representative Research Studies (Theoretical Framing)}

This section presents a selection of smartphone-related research studies that capture the unique nature of the investigations in this area. The studies were purposefully selected and not intended to be comprehensive. The descriptions pay special attention to the role of learning theory in the studies and the nuanced ways in which smartphone research makes an important and distinct contribution.

\subsection{Using CMC for Language Learning (Technology Acceptance Model)}

The Technology Acceptance Model (TAM) stipulates that the level of engagement with technology is based in part on perceived usefulness, ease of use, and attitude towards use [26]. The TAM has been used to investigate the utility of smartphones in a variety of disciplines, including language learning [27], information management [28], and technical education [29], and many others. One study used the TAM to compare computer-mediated communications (CMC; Facebook desktop chat) with mobile-mediated communications (MMC; WhatsApp) [27]. When comparing CMC and MMC, the researchers note that:

However, the existing literature tends to group this type of chat-based communication under the first categorization [CMC] without taking into consideration that the different functionalities, uses, and possibilities of each environment may affect the type of communication, engagement and language used among participants. These differences may be of interest to language practitioners and instructors when implementing blended learning strategies and language learning models in these environments and will be the subject of this investigation. (p. 3)

It is these differences between environments that reflect the need to better identify smartphone and learning research. This study found that Spanish students enrolled in an English course demonstrated higher levels of emotional engagement when utilizing MMC (via the smartphone). However, measures of cognitive engagement demonstrated advantages towards those using the desktop application.

In a related study, researchers developed a blended learning environment where smartphones were used as a flipped learning tool [30]. While much of the research implementing flipped learning had been carried out through the use of stationary devices, this research made use of the common characteristics of mobile devices to explore students' perceptions. The study used the technology acceptance model (TAM) and related measures to this aim. The scale used for this investigation was based on a TAM measure that addressed previous limitations, such as the influence of external variables or low levels of variance [31]. TAM scales such as this have been extensively used in mobile and computer-assisted language learning and typically address the following constructs: perceived ease of use, perceived usefulness, attitude towards use, behavioral intention, system characteristics, and material characteristics. These constructs were used to further understand students' acceptance and use of technology. Participants noted the advantages of the mobile phone for language learning and engaging in the 'flipped classroom'.

\subsection{Mobile Augmented Reality Learning Environment (Self-Determination Theory)}

A second common area of inquiry is the pedagogical use of the smartphone to support augmented reality. Smartphone-supported augmented reality can best be understood in relation to virtual reality. Virtual reality technology is becoming widely available in homes and schools [32]. The Meta corporation has reinvigorated interest in the technology with the promotion of the Oculus Quest 2, a head-mounted display and computer that permits the user to become immersed in a virtual 3-dimensional environment. Augmented reality differs in that it refers to technologies that support the integration of the physical and virtual environment [33]. The Augmented reality experience can be implemented with a common smartphone and does not require special equipment. A readily accessible example is the Google Translate camera function, which has been a tremendous tool for international travelers unfamiliar with local languages. Educators have long been interested in the utility 
of virtual and augmented reality for learning, and of late, researchers have increasingly sought to understand the implications [34]. As with the previous discussion of mobile mediated communications, smartphone-supported augmented reality provides unique opportunities to support learning.

Researchers have frequently used self-determination theory [35] to study the motivational implications of technologies. Self-determination theory relates student motivation to engage in activities based upon degrees of autonomy, competence, and relatedness perceived by the students. In a case study of a history lesson, researchers found that a mobile augmented reality learning environment implemented with the students' personal smartphones promoted intrinsic motivation [36]. The participants used the smartphone and an animation app to bring life to both animate historical images and also trigger informational videos. The study design capitalized on the autonomy and competence inherent in the learner's use of their own smartphone to increase motivation.

\subsection{Smartphone Use While Studying (Self-Regulated Learning)}

Recent research into the role of smartphones in the individual learning enterprise has produced some important findings [37,38]. These studies typically investigate how the smartphone hinders learning. Digital distractions while learning is one such area of inquiry. For example, receiving text messages on a smartphone has been shown to induce lower-quality lecture notes [39]. This study and others point to the need for students to self-regulate their behaviors while learning. This work is often conceptualized within selfregulated learning theory [40]. Study in this area has found that certain types of smartphone use while studying are closely related to self-regulated learning skills consistent with improved academic achievement [37]. One common measure of self-regulated learning, the Motivated Strategies for Learning Questionnaire (MSLQ), includes components specifically targeting time and effort towards learning [41]. The Smartphone and Learning Inventory (SALI) incorporates items addressing smartphone use while studying [42]. As one example of the relationship between self-regulated learning and smartphone use, students who scored higher on measures of effort regulation (e.g., "I work hard to do well in class") were more likely to interact with the smartphone while studying (e.g., "While studying, I pay attention to what is happening on social media").

\subsection{Why the Smartphone Is Different}

The concept of mobile learning emerged as students were becoming untethered by power and network connectors [16]. Concurrently, powerful devices were becoming smaller and more capable. In the ensuing two decades, non-mobile technologies of value to educators are limited enough to make the distinction unnecessary.

Learners are now in possession of a device that is always within reach and impacts all aspects of their life. The task for educational researchers is to provide a proper frame of reference to better understand the implications of this new reality. This task does not necessitate a reset of what has been learned to date regarding technology and learning. It does require new instantiations of existing learning theories and models. Self-determination theory, as one example, provides an excellent frame of reference for understanding motivation and learning [43]. The sense of autonomy generated by possession of the smartphone can be helpful in understanding the temptation to become over-reliant on the device.

In a similar vein, Self-regulated learning models of developing competence [44] can be used to assist learners in harnessing the power of the smartphone to support their learning [45]. The rapid adoption rate of the device has resulted in a generation of learners entranced by a device for which there is little understanding of the social and educational implications. For example, what does good studying look like in the presence of a smartphone? Again, models generated decades ago and withstood extensive research scrutiny may provide the appropriate lens needed to improve educational outcomes. 


\section{Discussion}

The goal of this paper is to better contextualize smartphone and learning research in the broader ICT research agenda. A review of the use of the descriptors m-learning for smartphone and learning research was conducted in support of this goal. The definitions and brief history of the terms smartphone and m-learning [14] explicated the distinctions. Next, the use of these descriptors in a sample of smartphone and learning research was presented. This overview suggests that smartphone and learning researchers are unsure of the proper classification of their research. In addition, providing smartphone-specific descriptors is infrequent when compared to m-learning. This is important because smartphone and learning research is expanding tremendously and exhibits attributes that are not clearly incorporated into definitions of m-learning.

The next section of the paper provided three examples of theory-driven smartphone and learning research that pay special attention to these unique characteristics. These include considerations supported by TAM, such as perceived ease of use and attitudes towards use. Research utilizing self-determination theory capitalized upon the capacity of the smartphone to engender student autonomy, competence, and relatedness. Finally, self-regulated learning models were used to understand the relationship between learners study habits and the use of the smartphone while studying. One common thread in this review of research is how ownership of the device supports activities that go beyond what was investigated in early instantiations of m-learning.

\subsection{Implications}

This paper presents evidence to support the importance of identifying the smartphone as a key area of inquiry in educational technology research. The terms mobile learning and m-learning are useful distinctions for educational researchers, and their use will continue. The primary value-added of these terms is to identify learning experiences that are not place-bound. The term smartphone may be the best term available to educational researchers interested in studying the role of a personal device for teaching and learning. In other words, the term smartphone is useful for educational researchers to target the implications of a primary computer that is personal to the user and within reach at all times. One important implication of this distinction is a recommended increase in the use of the term smartphone as a keyword for relevant studies. This practice will support the aggregation of ever-increasing smartphone and learning research in a manner that makes recommendations for practice more targeted and actionable.

Practitioners attempting to take advantage of ICT research are faced with difficulties in distinguishing between interventions that utilize personal technologies (e.g., personal smartphone) and those that utilize the classroom set of technologies (e.g., the classroom cart of iPads). There is a distinct shift occurring towards the former and away from the latter. While m-learning can capture all of this research, more specific nomenclature is necessary to focus on personal technologies.

\subsection{Limitations}

The primary limitation of this overview is the dependence upon secondary data. The use of the author-provided keyword descriptors is one of many possible ways to categorize research publications. Future analysis could utilize more detailed characteristics of work to support and identify categories. In addition, the selection of theoretical frameworks and representative studies was purposeful and not comprehensive. The research described was chosen to highlight how the uniqueness of the smartphone is often operationalized in common learning theories.

\subsection{Conclusions}

The shift towards the use of smartphones in support of learning is evident in the research being conducted and activities in classrooms [8]. The next steps include the continued development of evidence-based interventions that can be utilized in classrooms. The 
systematic development of instruction similar to what has been done with computational thinking can provide a recent and evidence-based model [46]. Strict adherence to instructional design models can support more efficacious interventions that take advantage of new capabilities available and are less vulnerable the continuing prior practices, which may now be outdated.

The smartphone will continue to play a significant role in the learning enterprise. This significance should be reflected in how educational research is conducted, described, and classified.

Author Contributions: Conceptualization, K.H. and A.A.; methodology, K.H. data curation, K.H.; writing—original draft preparation, K.H.; writing—review and editing, K.H., A.A. All authors have read and agreed to the published version of the manuscript.

Funding: This research received no external funding.

Informed Consent Statement: Not applicable.

Data Availability Statement: Web searches are available via links provided in Table 1.

Conflicts of Interest: The authors declare no conflict of interest.

\section{References}

1. Pew Research Center. Demographics of Mobile Device Ownership and Adoption in the United States. April 2021. Available online: https:// www.pewresearch.org/internet/fact-sheet/mobile/ (accessed on 13 July 2021).

2. US Census Bureau. Computer and Internet Access in the United States: 2012. The United States Census Bureau. 2012. Available online: https:/ /www.census.gov/data/tables/2012/demo/computer-internet/computer-use-2012.html (accessed on 14 July 2021).

3. US Census Bureau. American Community Survey Data. The United States Census Bureau. 2021. Available online: https: / / www.census.gov / programs-surveys/acs/data.html (accessed on 14 July 2021).

4. $\quad$ Dwyer, D.C.; Ringstaff, C.; Haymore, J.; Sandholtz, P.D. Apple classrooms of tomorrow. Educ. Leadersh. 1994, 51, 4-10.

5. Hartley, K.; Bendixen, L.D. Educational research in the internet age: Examining the role of individual characteristics. Educ. Res. 2001, 30, 22-26. [CrossRef]

6. $\quad$ Elhai, J.D.; Sapci, O.; Yang, H.; Amialchuk, A.; Rozgonjuk, D.; Montag, C. Objectively-measured and self-reported smartphone use in relation to surface learning, procrastination, academic productivity, and psychopathology symptoms in college students. Hum. Behav. Emerg. Technol. 2021, 3, 912-921. [CrossRef]

7. Wang, P.-Y.; Chen, K.-L.; Yang, S.-Y.; Lin, P.-H. Relationship of sleep quality, smartphone dependence, and health-related behaviors in female junior college students. PLoS ONE 2019, 14, e0214769. [CrossRef]

8. Wali, A.Z.; Omaid, M.E. The Use of Smartphones as an Educational Tool in the Classroom: Lecturers' Perceptions. Int. J. Emerg. Technol. Learn. IJET 2020, 15, 238-247. [CrossRef]

9. Saini, M.K.; Goel, N. How Smart Are Smart Classrooms? A Review of Smart Classroom Technologies. ACM Comput. Surv. 2019, 52, 1-28. [CrossRef]

10. Saikat, S.; Dhillon, J.S.; Wan Ahmad, W.F.; Jamaluddin, R.A. A Systematic Review of the Benefits and Challenges of Mobile Learning during the COVID-19 Pandemic. Educ. Sci. 2021, 11, 459. [CrossRef]

11. Mella-Norambuena, J.; Cobo-Rendon, R.; Lobos, K.; Sáez-Delgado, F.; Maldonado-Trapp, A. Smartphone use among undergraduate STEM students during COVID-19: An opportunity for higher education? Educ. Sci. 2021, 11, 417. [CrossRef]

12. Puttinaovarat, S. Online Learning Management During COVID-19 Pandemic: A Case Study of Geoinformatics Course Based on Cloud Application. TEM J. 2021, 10, 1104-1111. [CrossRef]

13. Hughes, G.T.G.; Camomilla, V.; Vanwanseele, B.; Harrison, A.J.; Fong, D.T.P.; Bradshaw, E.J. Novel technology in sports biomechanics: Some words of caution. Sports Biomech. 2021, 1-9. [CrossRef]

14. Traxler, J. Defining, Discussing and Evaluating Mobile Learning: The moving finger writes and having writ. Int. Rev. Res. Open Distrib. Learn. 2007, 8. [CrossRef]

15. Fu, Q.-K.; Hwang, G.-J. Trends in mobile technology-supported collaborative learning: A systematic review of journal publications from 2007 to 2016. Comput. Educ. 2018, 119, 129-143. [CrossRef]

16. Quinn, C. LiNE Zine-MLearning: Mobile, Wireless, In-Your-Pocket Learning. LineZine, Fall. 2000. Available online: http: //web.archive.org/web/20001109014500/www.linezine.com/2.1/features/cqmmwiyp.htm (accessed on 7 July 2021).

17. Korucu, A.T.; Alkan, A. Differences between m-learning (mobile learning) and e-learning, basic terminology and usage of m-learning in education. Procedia Soc. Behav. Sci. 2011, 15, 1925-1930. [CrossRef]

18. Brown, T.H.; Mbati, L.S. Mobile Learning: Moving Past the Myths and Embracing the Opportunities. Int. Rev. Res. Open Distrib. Learn. 2015, 16, 115-135. [CrossRef] 
19. Georgiev, T.; Georgieva, E.; Smrikarov, A. M-learning-a New Stage of E-Learning. In Proceedings of the International Conference on Computer Systems and Technologies-CompSysTech, Rousse, Bulgaria, 17 June 2004; Volume 4, pp. 1-4.

20. Lai, C.-L. Trends of mobile learning: A review of the top 100 highly cited papers. Br. J. Educ. Technol. 2020, 51, 721-742. [CrossRef]

21. Apple Newton. Wikipedia. 8 September 2021. Available online: https://en.wikipedia.org/w/index.php?title=Apple_Newton\& oldid $=1043062050$ (accessed on 22 September 2021).

22. Vailshery, L.S. Smartwatch Unit Sales in the US 2016-2020. Statista. 2021. Available online: https:/ /www.statista.com/statistics/ 381696/wearables-unit-sales-forecast-united-states-by-category/ (accessed on 22 September 2021).

23. Vogels, E.A. About One-In-Five Americans Use a Smart Watch or Fitness Tracker. Pew Research Center. 9 January 2020. Available online: https:/ / www.pewresearch.org/fact-tank/2020/01/09/about-one-in-five-americans-use-a-smart-watch-orfitness-tracker/ (accessed on 22 September 2021).

24. Asplund, S.-B.; Olin-Scheller, C.; Nilsberth, M. Under the teacher's radar: Literacy practices in task-related smartphone use in the connected classroom. L1 Educ. Stud. Lang. Lit. 2018, 18, 1-26. [CrossRef]

25. Kadry, S.; Roufayel, R. How to use effectively smartphone in the classroom. In Proceedings of the 2017 IEEE Global Engineering Education Conference (EDUCON), Athens, Greece, 25-28 April 2017; pp. 441-447.

26. Granić, A.; Marangunić, N. Technology acceptance model in educational context: A systematic literature review. Br. J. Educ. Technol. 2019, 50, 2572-2593. [CrossRef]

27. Andujar, A.; Salaberri-Ramiro, M.S. Exploring chat-based communication in the EFL class: Computer and mobile environments. Comput. Assist. Lang. Learn. 2019, 34, 434-461. [CrossRef]

28. Estrada Villa, E.J.; Marín, V.I.; Salinas, J. Research Skills for Information Management: Uses of Mobile Devices in Research Training. Educ. Sci. 2021, 11, 749. [CrossRef]

29. Mital', D.; Dupláková, D.; Duplák, J.; Mital'ová, Z.; Radchenko, S. Implementation of Industry 4.0 Using E-learning and M-learning Approaches in Technically-Oriented Education. Assoc. Inf. Commun. Technol. Educ. Sci. 2021, 10, 368-375. [CrossRef]

30. Andujar, A.; Salaberri-Ramiro, M.S.; Martínez, M.S.C. Integrating Flipped Foreign Language Learning through Mobile Devices: Technology Acceptance and Flipped Learning Experience. Sustainability 2020, 12, 1110. [CrossRef]

31. Chen Hsieh, J.S.; Wu, W.-C.V.; Marek, M.W. Using the flipped classroom to enhance EFL learning. Comput. Assist. Lang. Learn. 2017, 30, 1-21. [CrossRef]

32. Kim, J.; Palmisano, S.; Luu, W.; Iwasaki, S. Effects of Linear Visual-Vestibular Conflict on Presence, Perceived Scene Stability and Cybersickness in the Oculus Go and Oculus Quest. Front. Virtual Real. 2021, 2, 42. [CrossRef]

33. Azuma, R.T. A survey of augmented reality. Presence Teleoperators Virtual Environ. 1997, 6, 355-385. [CrossRef]

34. Buchner, J.; Buntins, K.; Kerres, M. A systematic map of research characteristics in studies on augmented reality and cognitive load. Comput. Educ. Open 2021, 2, 100036. [CrossRef]

35. Deci, E.L.; Ryan, R.M. Self-Determination Theory. In Handbook of Theories of Social Psychology; SAGE Publications Ltd.: London, UK, 2012; Volume 1, pp. 416-437.

36. Buchner, J.; Zumbach, J. Promoting Intrinsic Motivation with a Mobile Augmented Reality Learning Environment; International Association for the Development of the Information Society: Lisbon, Portugal, 2018. Available online: https://eric.ed.gov/?id= ED590357 (accessed on 17 April 2020).

37. Hartley, K.; Bendixen, L.D.; Gianoutsos, D.; Shreve, E. The Smartphone in self-regulated learning and student success: Clarifying relationships and testing an intervention. Int. J. Educ. Technol. High. Educ. 2020, 17, 52. [CrossRef]

38. Troll, E.S.; Friese, M.; Loschelder, D.D. How students' self-control and smartphone-use explain their academic performance Comput. Hum. Behav. 2021, 117, 106624. [CrossRef]

39. Flanigan, A.E.; Titsworth, S. The impact of digital distraction on lecture note taking and student learning. Instr. Sci. 2020, 48, 495-524. [CrossRef]

40. Zimmerman, B.J. Self-Regulated Learning: Theories, Measures, and Outcomes. In International Encyclopedia of the Social E Behavioral Sciences; Elsevier: Amsterdam, The Netherlands, 2015; pp. 541-546, ISBN 978-0-08-097087-5.

41. Pintrich, P.R.; Smith, D.; Garcia, T.; Mckeachie, W.J. A Manual for the Use of the Motivated Strategies for Learning Questionnaire (MSLQ). 1991. Available online: https:/ / eric.ed.gov/?id=ED338122 (accessed on 7 December 2020).

42. Hartley, K.; Bendixen, L.D.; Olafson, L.; Gianoutsos, D.; Shreve, E. Development of the smartphone and learning inventory: Measuring self-regulated use. Educ. Inf. Technol. 2020, 25, 4381-4435. [CrossRef]

43. Jeno, L.M.; Adachi, P.J.C.; Grytnes, J.-A.; Vandvik, V.; Deci, E.L. The effects of m-learning on motivation, achievement and well-being: A Self-Determination Theory approach. Br. J. Educ. Technol. 2019, 50, 669-683. [CrossRef]

44. Zimmerman, B.J. From Cognitive Modeling to Self-Regulation: A Social Cognitive Career Path. Educ. Psychol. 2013, 48, 135-147. [CrossRef]

45. Hartley, K. Smartphone-induced digital distractions: Using social cognitive theory and self-regulated learning to frame the challenge. In Digital Distractions in the College Classroom; Flanigan, A.E., Kim, J.H., Eds.; IGI Global: Hershey, PA, USA, 2022; ISBN 978-1-79989-243-4. Available online: https://www.igi-global.com/book/digital-distractions-college-classroom/www.igiglobal.com/book/digital-distractions-college-classroom/276928 (accessed on 12 October 2021).

46. Ling-Ling, U.; Labadin, J.; Mohamad, F.S. Information System Framework for Training Teachers on Computational Thinking. Sci. Res. J. 2021, 4, 119-127. [CrossRef] 